\title{
IDENTIFIKASI GASTROPODA DI SUB DAS ANAK SUNGAI GANDONG DESA KERIK TAKERAN
}

\author{
Mustika Wahyuning Tyas ${ }^{1)}$, Joko Widiyanto ${ }^{2)}$ \\ 1, 2) Program Studi Pendidikan Biologi FPMIPA IKIP PGRI Madiun \\ E-mail: joko_widiyanto@ymail.com
}

Diterima 3 September 2015 disetujui 15 Oktober 2015

\begin{abstract}
The aim of research to determine the diversity and Gastropod that predominate in sub watershed tributary village Gandong Takeran Kerik. Descriptive qualitative research method with type of observational study. Determination and site selection studies using transect sampling method, the size of $1 x 1 \mathrm{~m}$ transect quadrant. Research station at 3 stations with 3 points each station. The data was analyzed after identifying the calculation dominance index and diversity index. Gastropod identification results found 4 genera Thiara, Melanoides, Brotia, and Clea. The highest abundance of gastropods at station II, namely 13.7 ind/m2. Thiara highest dominance index is 0.654 , indicating that Thiara mendominansi in sub watershed tributary village Gandong Takeran Kerik. Diversity index of each station 0.617, 0.765, and 0.615, indicating that the diversity of gastropods in sub watershed tributary village Gandong Takeran Kerik is very low. Environmental parameters air temperature 30C-31C, 28C-29C water temperature, $\mathrm{pH} 7$ to 7.3, and dissolved oxygen (DO) $5 \mathrm{mg}$ ll - 5,4mg $/$.
\end{abstract}

Keywords: Gastropod, diversity, Gandong

\section{PENDAHULUAN}

Gastropoda termasuk dalam kelasMollusca, yang menggunakan perut untuk bergerak. Gastropoda banyak ditemukan di perairan air tawar, air laut, dan darat. Gastropoda air tawar banyak ditemukan di habitat yang berlumpur, yang aliran airnya cukup deras, dan sebagian ada yang terdapat pada persawahan yang sebagai hama bagi tanaman padi (Wahyono, 2005). Populasi Gastropoda sangat di pengaruhi oleh kondisi fisik dan kimia dari perairan di lingkungan tersebut.

Daerah Aliran Sungai (DAS) juga merupakan satu satu kesatuan dengan sungai dan anak sungainya, yang berfungsi menampung, menyimpan, dan mengalirkan air yang berasal dari curah hujan ke danau atau ke laut secara alami, serta masih terpengaruh aktivitas daratan (Dwi, 2011). DAS yang terkenal salah satunya yaitu DAS Bengawan Solo, yang memiliki beberapa SUB DAS antara lain Kali Madiun. Kali Madiun memiliki beberapa SUB DAS yang antara lain Sungai Gandong di Kabupaten Magetan, yang melewati Desa Kerik Kecamatan Takeran Magetan. Isnaeni (dalam Rakhmanda, 2011) berpendapat bahwa kehidupan di sungai dijumpai tidak hanya pada badan sungai, tetapi juga pada dasar sungai yang padat. dasar sungai, jumlah kehidupan sangat terbatas karena ketersediaan nutrient yang terbatas, maka hewan yang hidup di air dalam hanya hewan-hewan yang dapat hidup dengan jumlah dan jenis nutrient terbatas. Pratiwi dkk., (dalam Rakhmanda, 2011) menyampaikan bahwa hewan-hewan yang dapat hidup dengan keterbatasan tersebut yaitu makrozoobentos yang meliputi kijeng, kerang, cacing pipih, Gastropoda (siput yang tanpa operkulum, dan siput yang memiliki operkulum).

Hasil penelitian Hartoni dan Andi (2013) tentang kelimpahan Gastropoda dan Bivalvia di Ekosistem Mangrove Muara Sungai menemukan sebanyak 12 Family yaitu Bullidae, Cerithiidae, Muricidae, 


\section{Ellobiidae, Planaxidae, Littorinidae, Pengamatan dan Identifikasi Melampidae, Mitridae, Naticidae, Neritidae, Potaminididae, dan Synceriidae. \\ Gastropoda \\ Selanjutnya gastropoda yang telah} Sedangkan penelitian tentang identifikasi populasi Gastropoda yang dilakukan oleh Sri Wahyono (2005) di Waduk Saguling menemukan 6 spesies Gastropoda yaitu Pomaceae caniculata, Bellamya javanica, Lymnaea rubiginosa, Indoplanorbis exustus, Gyraulus convexiusculus, dan Melanoides tuberculata.

\section{METODE}

Metode penelitian dilakukan secara deskriptif kualitatif dengan jenis penelitian observasi. Lokasi pengambilan sampel Gastropoda di Sub Sub DAS Anak Sungai Gandong Desa Kerik Takeran Magetan pada bulan April 2015.

\section{Prosedur Pengambilan Sampel}

Langkah-langkah yang dilakukan dalam pengambilan sampel yaitu metode line transek dengan membuat 3 stasiun sepanjang garis transek dengan jarak $100 \mathrm{~m}$ antar stasiunnya, dan tiap stasiun memiliki 3 titik dengan jenis metode kuadran $1 \mathrm{x} 1 \mathrm{~m}$. Pengambilan sampel dilakukan dengan cara aduk badan sungai dan dinding sungai yang menjorok ke dalam dengan cara menginjak-injak dan menggoyanggoyangkan, pada substrat bebatuan tempatkan jaring pada tempat yang mudah dijangkau dan diambil Gastropoda, pada substrat pasir tempatkan jaring sedikit di atas dasar sungai agar pasir tidak banyak pasir yang terbawa, dan yang menempel pada batang, kayu, atau bebatuan bisa langsung diambil. Pengambilan sampel dilakukan pada pagi dan sore hari setiap stasiunnya. Gastropoda yang ditemukan kemudian diawetkan dalam alkohol $70 \%$ dan formalin $0,4 \%$. Bersamaan dengan pengambilan sampel dilakukan pengukuran parameter lingkungan meliputi suhu udara, suhu air, $\mathrm{pH}$, dan $\mathrm{DO}$ pada masing-masing stasiun. didapatkan diawetkan kemudian diamati ciri-ciri morfologi serta diidentifikasi menurut petunjuk Freshwater Snails (Mollusca: Gastropoda) of North America. Pengarang J. B. Burch (1982).

\section{Analisis Data}

Teknik analisis data dilakukan untuk mengetahui kemelimpahan gastropoda, nilai indeks dominansi, dan nilai indeks keanekaragaman. Kemelimpahan individu gastropoda dihitung menggunakan rumus Shannon-Wener Odum (1993) (dalam Wulan Suci, dkk, 2012).

$\mathrm{Y}=\frac{10000 \times \mathrm{a}}{\mathrm{b}}$

yaitu $\mathrm{Y}=$ kemelimpahan $\left(\mathrm{ind} / \mathrm{m}^{2}\right.$ )

$\mathrm{a}=$ jumlah individu seluruhnya (ind)

$\mathrm{b}=$ Luas kuadran $\left(\mathrm{m}^{2}\right)$

Jika indeks dominansi (C) mendekati 0 berarti hampir tidak ada individu yang mendominansi dan jika indeks dominansi (C) mendekati 1 bearti salah satu genera yang mendominansi.

Indeks keanekaragaman dapat dihitung menggunakan rumus Shanon-Wiener Koesoebiono (1987) (dalam Wulan Suci, dkk, 2012).

$\mathrm{H}^{\prime}=-\Sigma \stackrel{i}{\ln }$

Kategori penilaian tingkat keanekaragaman jenis berdasarkan indeks dominansi adalah $\mathrm{H}^{\prime} \leq 1$ = Keanekaragaman sangat rendah

$1 \leq \mathrm{H}^{\prime} \leq 1,59=$ Keanekaragaman rendah

$1,6 \leq \mathrm{H}^{\prime} \leq 2$ = Keanekaragaman sedang

$\mathrm{H}^{\prime}>2=$ Keanekaragaman tinggi

\section{HASIL DAN PEMBAHASAN}

Hasil penelitian identifikasi gastropoda di Sub DAS Anak Sungai Gandong Desa Kerik Takeran ditemukan 3 famili antara lain sebagai berikut. 


\section{Famili Thiaridae}

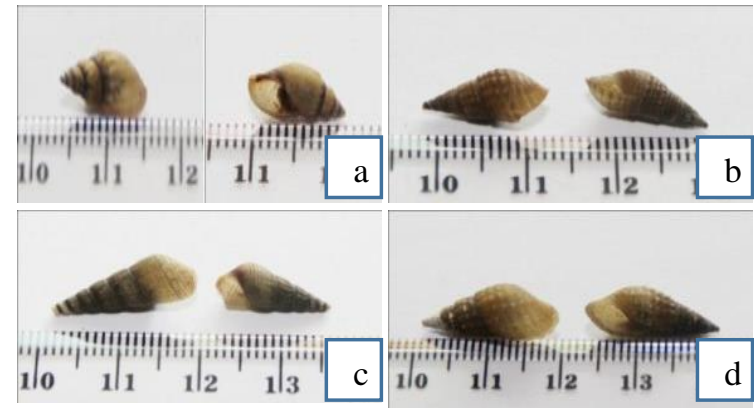

Gambar 1. Genus Thiara (a,b), Genus Melanoides (c), Genus Melanoid (d)

Genus Thiara pengamatan morfologi gastropoda yang memiliki ciri panjang 1-2 $\mathrm{cm}$, tempurung bermenara, permukaan luarnya dengan pergoresan kasar dan lapisan luarnya memiliki bintil, berwarna coklat muda, kecoklat- coklatan hitam, dan kuning terang (J. B. Burch, 1982). Kunci determinasi menurut J. B. Burch (1982) sebagai berikut: 1-2-8-8(2)............Genus Thiara. Genus Thiara menunjukkan pengamatan morfologi gastropoda yang memiliki ciri panjang 1-4 cm, tempurung memanjang dengan ulir utama membesar, lapisan luar memiliki bintil, berwarna coklat hingga kehitaman dan putih bercak-cak coklat (J. B. Burch,1982). Kunci determinasi menurut J. B. Burch (1982) sebagai berikut: 1-2-88(1)....................enus Melanoides. Famili Thiaridae paling banyak ditemukan di Sub Sub DAS Anak Sungai Gandong. Hal ini sesuai dengan penelitian Z. Suspian and A. M. Ikhwannudin (2002) bahwa tempurung famili Thiaridae menunjukkan keistimewaan struktur tertentu sebagai respon kehidupannya di perairan mengalir.

\section{Famili Pleuroceridae}

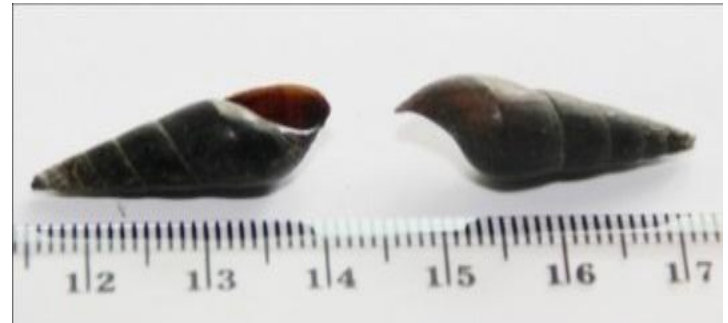

Gambar 2. Genus Brotia

Genus Brotia pengamatan morfologi gastropoda yang memiliki ciri panjang 22$40 \mathrm{~mm}$, tempurung memanjang kerucut, padat, bagian ulir utama membesar, permukaan cangkang halus, padat, dan tebal, berwarna gelap dari kecoklatan hingga hitam, kuning hingga coklat, dan kecoklat-coklatan nyala (Ristiyanti M.M dan Nur R.I, 2012). Kunci determinasi menurut J. B. Burch (1982) sebagai berikut: 1-2-5-34-36..........Genus Brotia.

\section{Famili Buccinidae}

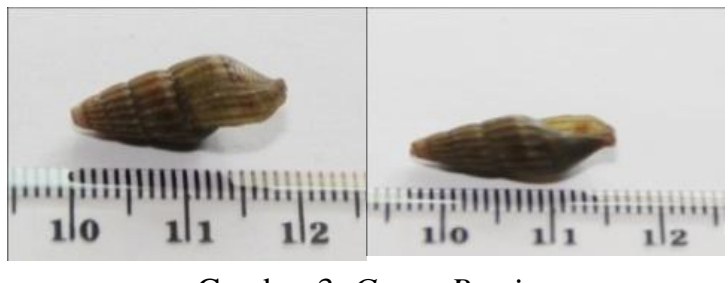

Gambar 3. Genus Brotia

Genus Clea menunjukkan pengamatan morfologi gastropoda yang memiliki ciri panjang 1-3 cm,permukaan cangkang bergelombang membentuk garisgaris, cangkang berwarna coklat muda dan coklat tua berselang seling (J. B. Burch, 1982). Kunci determinasi menurut J. B. Burch (1982) sebagai berikut: 1-2-34. Genus 
Tabel 1. Klasifikasi Gastropoda

\begin{tabular}{llllll}
\hline Phylum & Kelas & Sub Kelas & Ordo & Famili & Genus \\
\hline Mollusca & Gastropoda & Prosobranchia & Sorbaeconcha & Thiaridae & Thiara \\
& & & & Melanoides \\
& & & Pleuroceridae & Brotia \\
& & & Buccinidae & Clea \\
\hline
\end{tabular}

Tabel 2. Parameter lingkungan

\begin{tabular}{lccc}
\hline Parameter & Stasiun I & Stasiun II & Stasiun III \\
\hline Suhu udara & $31^{\circ} \mathrm{C}$ & $30^{\circ} \mathrm{C}$ & $30,5^{\circ} \mathrm{C}$ \\
Suhu air & $29^{\circ} \mathrm{C}$ & $28,5^{\circ} \mathrm{C}$ & $28^{\circ} \mathrm{C}$ \\
pH & 7,3 & 7 & 7,2 \\
DO & $5,2 \mathrm{mg} / 1$ & $6,1 \mathrm{mg} / 1$ & $5,4 \mathrm{mg} / 1$ \\
\hline
\end{tabular}

Tabel 3. Tabel Hasil Pengamatan Keanekaragaman Gastropoda

\begin{tabular}{|c|c|c|c|c|c|c|c|c|c|c|c|c|}
\hline \multirow[t]{2}{*}{ No. } & \multirow[t]{2}{*}{ Genus } & \multicolumn{3}{|c|}{ Stasiun I } & \multicolumn{3}{|c|}{ Stasiun II } & \multicolumn{3}{|c|}{ Stasiun III } & \multirow{2}{*}{ Jumlah } & \multirow{2}{*}{$\begin{array}{l}\text { Nilai toleransi } \\
\text { (ti) }\end{array}$} \\
\hline & & 1 & 2 & 3 & 1 & 2 & 3 & 1 & 2 & 3 & & \\
\hline 1 & Thiara & 152 & 40 & 34 & 180 & 94 & 43 & 132 & 61 & 44 & 780 & 6 \\
\hline 2 & Melanoides & 12 & 8 & 6 & 22 & 17 & 8 & 18 & 7 & 3 & 101 & 6 \\
\hline 3 & Brotia & 5 & 6 & 4 & 18 & 8 & 5 & 7 & 4 & 3 & 60 & 6 \\
\hline 4 & Clea & 6 & - & - & 9 & 4 & 3 & 7 & - & - & 29 & 8 \\
\hline \multicolumn{2}{|c|}{ Jumlah } & 175 & 54 & 44 & 229 & 123 & 59 & 164 & 72 & 50 & 970 & - \\
\hline
\end{tabular}

Tabel 4. Parameter lingkungan

\begin{tabular}{lcccc}
\hline Genus & Stasiun I & Stasiun II & Stasiun III & $\Sigma$ indeks Dominansi \\
\hline Thiara & 0,683 & 0,594 & 0,685 & 0,654 \\
Melanoides & 0,0090 & 0,0129 & 0,0094 & 0,0140 \\
Brotia & 0,0029 & 0,0059 & 0,0029 & 0,0029 \\
Clea & 0,0004 & 0,0014 & 0,0006 & 0,0006 \\
\hline
\end{tabular}

Berdasarkan Tabel 2 parameter lingkungan tempat penelitian masih terlihat baik untuk perkembangbiakan dari gastropoda dengan suhu udara berkisar antara $30-31^{\circ} \mathrm{C}$, suhu air $28-29^{\circ} \mathrm{C}, \mathrm{pH} 7$ 7,3, dan DO 5,2-6,1 mg/l.

Berdasarkan Tabel 3 menunjukkan bahwa Genus Thiara paling banyak ditemukan, sedangkan yang paling jarang ditemukan Genus Clea. Stasiun II yang paling banyak ditemukan gastropoda, hal ini karena habitatnya yang banyak bebatuan sehingga gastropoda dapat menempel pada bebatuan dan memiliki substrat yang berlumpur dan berpasir sehingga memiliki cadangan makanan yang cukup bagi gastropoda, serta memiliki parameter lingkungan suhu udara $30^{\circ} \mathrm{C}$, suhu air $28,5^{\circ} \mathrm{C}, \mathrm{pH} 7$,dan DO 6,1 mg/l. Selain itu juga dipengaruhi oleh substrat tiap stasiun, karena pada dasar substrat memiliki kandungan bahan organik sebagai cadangan makanan bagi gastropoda. Substrat yang berlumpur memiliki lebih banyak kandungan bahan organik daripada substrat yang berpasir, hal ini didukung oleh Sari (dalam Wulan, 2012) bahwa bahan organik yang mengendap di dasar perairan merupakan sumber makanan bagi organisme bentik, sehingga jumlah dan laju pertambahannya mempunyai pengaruh terhadap populasi organisme dasar.

Kemelimpahan gastropoda pada stasiun I rendah disebabkan tidak banyaknya bebatuan untuk menempel, karena gastropoda banyak dijumpai menempel pada bebatuan, atau kayu, tingginya aktifitas manusia seperti 
pengambilan pasir dan batuan sehingga mempengaruhi kehidupan biota pada stasiun I , memiliki substrat yang berpasir sehingga kurang memiliki bahan organik untuk cadangan makanan bagi gastropoda, serta memiliki parameter lingkungan Dissolved Oxygen (DO) pada stasiun I rendah yaitu 5,2 $\mathrm{mg} / \mathrm{l}$, karena stasiun I substratnya berupa pasir yang banyak sehingga kadar oksigennya rendah. Hal ini didukung penelitian Andhika Rakhmanda (2011:5) bahwa ukuran partikel yang sangat halus disertai dengan sudut dasar sedimen yang datar menyebabkan air di dalam sedimen tidak mengalir keluar dan tertahan di dalam substrat, sehingga akan menghasilkan penurunan kadar oksigen. Semakin tinggi sedimentasi maka semakin berkurang kandungan oksigen terlarut. Kemelimpahan gastropoda pada stasiun III sedang yaitu 9,53 ind $/ \mathrm{m}^{2}$ disebabkan karena habitatnya banyak bebatuan untuk menempel,, tetapi memiliki substrat berpasir sehingga kurang memiliki bahan organik untuk cadangan makanan bagi gastropoda, dan memiliki parameter lingkungan suhu udara $30,5^{\circ} \mathrm{C}$, suhu air $28^{\circ} \mathrm{C}, \mathrm{pH} 7,2$, dan DO 5,4 mg/l.

Tabel 5. Analisis nilai indeks keanekaragaman

\begin{tabular}{lc}
\hline Stasiun pengambilan & $\begin{array}{c}\text { Indeks } \\
\text { keanekaragaman }\end{array}$ \\
\hline Stasiun I & 0,617 \\
Stasiun II & 0,765 \\
Stasiun III & 0,615 \\
\hline
\end{tabular}

Berdasarkan Tabel 5 menunjukkan indeks keanekaragaman (H') gastropoda di SubSub Das Anak Sungai Gandong Desa Kerik Takeran berkisar antara 0,615-0,765. Stasiun I nilai indeks keanekaragaman $\left(\mathrm{H}^{\prime}\right)$ yaitu $0,617 \leq 1, \quad$ maka keanekaragamannya sangat Rendah, Stasiun II nilai indeks keanekaragaman yaitu $0,765 \leq 1$, maka keanekaragamannya sangat rendah, stasiun III nilai indeks keanekaragaman yaitu $0,615 \leq 1$, maka keanekaragamannya sangat rendah.
Nilai Indek Dominansi (C) yang tinggi pada Genus Thiara akan berhubungan dengan nilai indeks keanekaragaman $\left(H^{\prime}\right)$ yang rendah. Poole (dalam Jakomina, 2011) menjelaskan bahwa keanekaragaman tidak hanya bergantung dari jumlah spesies atau genera dalam suatu komunitas tetapi juga tergantung dari kemelimpahan setiap spesies atau genera. Odum (dalam Wulan, 2012) menyatakan bahwa keanekaragaman mencakup dua hal penting yaitu banyak jenis dalam suatu komunitas dan kelimpahan dari masing-masing jenis, sehingga semakin kecil jumlah jenis dan variasi jumlah individu tiap jenis memiliki penyebaran yang tidak merata, maka keanekaragaman akan mengecil.

Sebagian hasil penelitian identifikasi gastropoda dijadikan sebagai petunjuk praktikum Mata Kulian Taksonomi Hewan Invertebrata. Berdasarkan hasil validasi yang telah dilakukan, buku petunjuk praktikum Taksonomi Hewan Invertebrata memperoleh nilai akhir 62, dengan rata- rata total 31. Prosentase rata-rata petunjuk praktikum yaitu $77,5 \%$, maka dapat dikategorikan bahwa bahan penyusun petunjuk praktikum "cukup layak" untuk dijadikan buku petunjuk praktikum.

\section{SIMPULAN}

Berdasarkan penelitian identifikasi Gastropoda di Sub DAS Anak Sungai Gandong Desa Kerik Takeran maka dapat disimpulkan bahwa Gastropoda yang ditemukan di Sub Sub Das Anak Sungai Gandong Desa Kerik Takeran terdiri dari 3 famili, 4 Genus yaitu Genus Thiara, Genus Melanoides, Genus Brotia, dan Genus Clea. Berdasarkan nilai indeks dominansi Genus Thiara memiliki nilai yang paling tinggi yaitu 0,654 mendekati 1, sehingga Genus Thiara yang mendominasi di Sub Sub Das Anak Sungai Gandong Desa Kerik Takeran 


\section{DAFTAR PUSTAKA}

Dwi Putri. (2011). Kebijakan Pemerintah Dalam Pengendalian Pencemaran Air Sungai Siak (Studi pada Daerah Aliran Sungai Siak Bagian Hilir). Dosen Program Studi Ilmu Pemerintahan, Fakultas Ilmu sosial dan Ilmu Politik Universitas Maritim Raja Ali Haji. Jurnal Ilmu Politik dan Ilmu Pemerintahan, Vol. 1, No. 1

Hartoni dan Agussalim. (2013). Komposisi dan Kemelimpahan Moluska (Gastropoda dan Bivalvia) di Ekosistem Mangrove Muara Sungai Musi Kabupaten Banyuasin Provinsi Sumatera Selatan. Maspari Journal. 5 (1), 615.

Jakomina, M, Juliana, M. Y. Beruatjaan. (2011). Kelimpahan Gastropoda pada Habitat Lamun Di Perairan Teluk Un Maluku Tenggara. Makalah disajikan dalam Prosiding Seminar Nasional Pengembangan Pulau-pulau Kecil. Program Studi Budidaya Perairan, Politeknik Perikanan Negeri Tual. ISBN: 978-602-98439-2-7.

J. B. Burch. (1982). Freshwater Snails (Mollusca: Gastropoda) Of North America. Environmental Monitoring and Support Laboratory Office of Research and Development U.S. Environmental Protection Agency Cincinnati, Ohio 45268.

Rakhmanda, A. (2011). Estimasi Gastropoda di Sungai Tambak Bayan Yogyakarta. Jurnal Ekologi Perairan. Laboratorium Ekologi Perairan Jurusan Perikanan
Fakultas Pertanian UGM.No. 1:1-7. Ristiyanti M. Marwoto and Nur R. Isnaningsih. (2012). The Freshwater Snail Genus Sulcospira Troschel, 1857 From Java, With Description Of A New Species From Tasikmalaya, West Java, Indonesia (Mollusca: Gastropoda: Pachychilidae). THE RAFFLES BULLETIN OF ZOOLOGY 2012 60 (1): 1-10.

Stevi Mardiani M. Maruru. (2012). Studi Kualitas Air Sungai Bone Dengan Metode Biomonitoring. Jurusan Kesehatan Masyarakat, Fakultas Ilmu-Ilmu Kesehatan Dan Keolahragaan, Universitas Negeri Gorontalo.

Wahyono, S. (2005). Identifikasi Populasi Gastropoda Air Tawar di Waduk Seguling dan sekitarnya. Jurnal Teknologi Lingkungan P 3 TL-BPPT, 6. (1): 274-282.

Wulan, S., W.Retna Melani, dan T.Said Raza'i. 2012. Struktur Komunitas Moluska Bentik Berbasis TDS (Total Dissolved Solid) Padatan Terlarut dan TSS (Total Suspended Solid) Padatan Tersuspensi di Pesisir Perairan Sungai Kawal Kabupaten Bintan

Supian and Ikhwanuddin. (2002). Population Dynamics Of Freshwater Molluscs (Gastropod: Melanoides Tuberculata) In Crocker Range Park, Sabah. ASEAN Review of Biodiversity and Environmental Conservation (ARBEC). 